Original Research Paper

\title{
A New Look at Our Old Attitude Problem
}

\author{
Rajvinder Samra \\ Department of Primary Care and Public Health, Imperial College London, W6 8RP, United Kingdom
}

Article history

Received: 30-09-2014

Revised: 24-10-2014

Accepted: 10-12-2014

\begin{abstract}
Across the disciplines, attitudes are commonly measured through the use of unidimensional scaling (e.g., Likert scaling). Given that the Likert measurement scale (multiple equivalent items regarding an attitudinal target from which a summated score is produced) and the Likert response format (positive to negative judgements) were developed over 80 years ago, this article questions whether Likert scaling is still optimal for attitude investigation. In this article, it is argued that the lack of resolution of the debate around the dimensionality of attitudes has encouraged a simplistic view of attitudes (assumed unidimensionality of both attitudes and attitudes responses) to predominate, without empirical justification for this view.
\end{abstract}

Keywords: Attitudes, Attitude Theory, Dimensionality, Attitude Structure

\section{Introduction}

\section{Definition of an 'Attitude'}

In 1958, Allport (1979) commented that an attitude "is probably the most distinctive and indispensable concept in contemporary American social psychology" (p. 43). Despite the importance of the attitude concept, its definition at this time was still undergoing transformation. One of the first attempts to define an 'attitude' in the scientific research literature included an examination of 183 books and articles and concluded that there were 23 different definitions of an attitude as a scientific concept (Nelson, 1939). Nelson noted that some definitions of an attitude could not be differentiated from a 'habit', 'disposition', 'tendency' or an 'opinion' and concluded that an accepted definition of an attitude had not been reached. In 1963, another review on the state of the scientific literature indicated that the attitude concept "is still in a surprisingly crude state of formulation considering its widespread use. At best it barely qualifies as a scientific concept" (DeFleur and Westie, 1963). The authors recommended further development, rather than abandonment of the concept altogether. Subsequent to this, attitude theory from the 1960 $\mathrm{s}$ demonstrated remarkable and accelerated refinement of the attitude concept, most notably in the increasing specificity of the attitude definition. More recently, attitudes are typically described as evaluation toward a target, along a continuum ranging from favourable to unfavourable (Eagly and Chaiken, 1993; Zanna and Rempel, 1988). In order to understand the reasons for the increased specificity and reduced breadth of the attitude concept as it is often described today, it is necessary to consider the debate on attitude structure.

\section{Attitude Structure: The Unidimensional Model vs. the Tripartite Model Debate Begins}

The belief that an attitude is "a psychological tendency that is expressed by evaluating a particular entity with some degree of favor or disfavor" (Eagly and Chaiken, 1993) is based on the unidimensional model of attitude structure. This model assumes that all the information contributing to the resultant attitude lies on the same single evaluative dimension, varying from positive (favourable) to negative (unfavourable). As a result, an attitude has been likened to an evaluative summary of information on a target (Fazio, 2007). Measurement scales that use total summated scores implicitly assume an attitude can be captured as a single point along a preference scale (ranging from positive to negative) are based on the unidimensional view (Edwards, 1957; Likert, 1932; Thurstone and Chave, 1929). Although assumed, unidimensionality is not always found; Duncan and Stenbeck (1987) found that Likert items with a Likert response format produced two-dimensional data, content-by-intensity. Their data demonstrated that attitudes varied according to content (agree or disagree) and intensity (strongly or not strongly). Interestingly, this supports a hypothesis made decades earlier by Sherif et al. (1965), who stated that a single total attitude score can only identify level of attitude acceptance and cannot indicate how close an unacceptable position was to the stand an individual took, or how unacceptable or acceptable other positions were.

Despite the common use of attitude scales that are based on the unidimensionality of attitudes, the model underpinning such scales has been heavily criticised in the past. Diab (1967) has argued that it is not 
realistic to consider that an individual's attitude can be adequately represented by an average score on a preference scale along a continuum of positive to negative evaluations. The most common criticism levelled at the unidimensional model of attitude structure is that it is unlikely that two individuals who score the same preference for a target have the same exact attitude towards the target (Diab, 1967). At the very least, an attitude is a statement of the most acceptable position to an individual regarding his or her views on a target (Diab, 1967). In deciding the most acceptable position, the individual has a relationship to all the positions which he or she rejected as unacceptable, which Diab (1967) argues is informative about the attitude. However, this data is not gathered as part of the preference score data which represents overall acceptability (liking; preference) and does not collect and score unacceptability (disliking) separately. (Although Likert scales use bipolar scaling, the attitude results are typically the net positive or negative responses).

Although attitude scales and measurement techniques for capturing attitudes often implicitly assume the unidimensional model of attitude structure, the scientific research literature dedicated to exploring attitude structure has tended to regard attitudes as multidimensional (Tesser and Shaffer, 1990) since the $1940 \mathrm{~s}$ (Smith, 1947). The late $1940 \mathrm{~s}$ saw the birth of a three-component model of attitude structure, also referred to as the tripartite model and refinement of this model continued throughout the $1950 \mathrm{~s}$ (Katz and Stotland, 1959) and 1960 s (Ostrom, 1969; Rosenberg and Hovland, 1960; Triandis, 1967). Smith (1947) was amongst the first to describe the components of the tripartite model in a study investigating attitudes towards Russia in 1947. Smith (1947) argued that his analysis demonstrated multiple components of attitudes; specifically (a) how a person feels towards the subject (affective); (b) what a person thinks about the subject (cognitive); and (c) what actions should be taken (termed 'policy orientation' in Smith's article and later referred to by others as behavioural, Rosenberg and Hovland, 1960). Smith (1947) argued that these findings supported the use of this conceptual model as a framework for the investigation of complex attitudes.

Following further development during the $1950 \mathrm{~s}$, the tripartite model of attitudes was then formally outlined by Rosenberg and Hovland (1960). According to this model, attitudes consist of three different classes of information; (a) affective (feelings toward the target), (b) behavioural (past and future behavioural intentions in relation to the target) and (c) cognitive (beliefs or stereotypes about the target). The tripartite model of attitudes posits that the contents of these three sources of information are the attitude (Rosenberg and Hovland, 1960). In contrast, the unidimensional model assumes that the attitude is a general evaluative summary, which is separate and distinct from, but can be based on affective, behavioural and cognitive information (Eagly and Chaiken, 1993). Despite the fact that the tripartite model is sometimes referred to as the threecomponent view of attitudes (Ajzen, 2014; Zanna 1990; Eagly and Chaiken, 1993); this is misleading for two reasons: Firstly, those taking the unidimensional view can still believe that attitudes have three components (similar to a single product having three ingredients as its components). Secondly, the tripartite model is more accurately a three-dimensional (or trivariate) model of attitudes because the contributing components are conceptually distinct. In the early research, the three components/dimensions (henceforth, referred to as 'components' for consistency) were measured using separate scales with different response formats for each: For example, the use of a semantic differential for measurement of the cognitive component, the use of particular behaviours with a dichotomous response format for the behavioural component and a Likert response format for the affective component (indicating favourableunfavourable judgments). The use of different response formats for the attitude components in past research was due to the received view being that the three components are qualitatively different (i.e., dimensions) (Breckler, 1984; Breckler and Wiggings, 1989; Ostrom, 1969). In contrast, using the same Likert response format (favourable to unfavourable) for all three components would suggest that they are quantitatively different but not qualitatively different sources of information (because they can be measured on the same scale).

In order to resolve the unidimensional versus tripartite model debate, Ostrom (1969) offered statistical support for the existence of three components of attitudes, as outlined in the tripartite model. Ostrom (1969) study used a multitrait-multimethod design (Campbell and Fiske, 1959) and therefore used multiple measures of the hypothesised constructs of affective, behavioural and cognitive information. Ostrom (1969) measured attitudes using equal-appearing intervals (Thurstone and Chave, 1929), summated rating scales (Likert, 1932), a scalogram analysis (Guttman, 1944) and a self-rating scale (Guilford, 1954). Using the four different methods of attitude measurement for each of the three components of the tripartite model, Ostrom (1969) sought to determine whether each component correlated with itself (as measured by a different scale) as opposed to correlating with either of the other two components (as measured by any scale). Ostrom (1969) found evidence for the unique additional variance for the three components over the shared variance of the combined three components and therefore found statistical support for the tripartite model. He did note that the unique additional variance of the three 
components was small and this was confirmed in a later reanalysis of the data (Bagozzi, 1978). Importantly, one of the main strengths of the tripartite model is the statistical validation it has received (Breckler, 1984; Breckler and Wiggins, 1989; Woelfel et al., 1980).

\section{The Growing Dominance of the Unidimensional View of Attitudes}

Despite the aforementioned early statistical validation of the tripartite model (Breckler, 1984; Ostrom, 1969), studies measuring attitudes have consistently and increasingly assumed unidimensionality, through the use of unidimensional scaling such as Likert scales (e.g., (Baum and Nelson, 2007; Gjersing et al., 2010; Macknight and Powell, 2001; Reuben et al., 1998; Wånggren et al., 2013). In other words, research typically produces an average or summated score, along a single scale, despite the statistical evidence that the scores represent different components of an attitude (Ostrom, 1969). Ostrom (1968) has argued that this evaluative dimension measured by these scales, specifically the preference for or against a target along a continuum (favourable or unfavourable judgements), may simply represent the affective component of the tripartite model. The move away from the tripartite model of attitude structure was described by Ostrom (1968): "The bulk of attitude research and consequently, the theory developed to understand the attitude change process, continues to focus primarily on affect to the detriment of understanding the other characteristics of attitude" (p. 27). Ostrom (1968) essentially argued that attending to only one of the three components missed valuable information on the attitude and reduces validity of subsequent measurement.

Whilst it appears that attitudes measures address affective, behavioural and cognitive information due to the choice of questionnaire items, the use of the same unidimensional scaling technique for the response format (e.g., strongly agree to strongly disagree) means that the measure does not. Whilst affect can be determined using favourability ratings (ranging from positive to negative), behaviour may be better measured by level or extent of engagement in particular behaviours regarding an attitudinal target (rather than preference for and against particular behaviours); cognitive information may be better measured by determining semantic links to an attitudinal target (rather than author-defined positive and negative judgements/beliefs about the target). Alternatively, an open-response format can be used to determine the most salient and pervasive responses for each component in relation to the attitudes in question (Bell et al., 1996; Esses and Maio, 2002; Haddock and Zanna, 1998; Esses et al., 1994).

Another account of the movement towards assuming the unidimensionality of attitudes, despite the statistical support for the tripartite model, relates to the ease and convenience of taking a unidimensional view. Writing in (Fishbein, 1967) argued that the definition of an attitude should be closer in line with the techniques of measurement of attitudes at the time, rather than the other way around. Fishbein (1967) went on to justify the use of the measurement of only one component of the tripartite model (the affective component) because it was easier to employ rigorously and created less problems than multidimensional concepts. Fishbein (1967) concluded, "a conceptual system in which only the affective component is treated as attitudinal and the other two components are linked to beliefs, should permit a more productive approach to the study of attitudes" (p. 257).

Similarly, Triandis (1967) has claimed that the tripartite model fell out of favour due to a lack of adequate procedures for attitude measurement, rather than any particular weakness associated with its underlying theory. In contrast, research assuming a unidimensional view in which attitudes vary on a single evaluative dimension, from favourable to unfavourable, had a number of possible techniques in which attitudes could be measured consistent with this view (Guttman, 1944; Likert, 1932; Thurstone and Chave, 1929). The most popular attitude measurement scales, the summative or Likert (1932), the equally-appearing intervals or Thurstone (1928) and the cumulative or Guttman (1944) do not conceptually distinguish between attitudinal response data because all responses are measured on a scale that varies on a single dimension of favourable to unfavourable. Therefore on the unidimensional scales, a behavioural-related attitudinal response is treated the same as a cognitive-related attitudinal response and it is assumed that all data varies from unfavourable to favourable in the same way (McIver and Carmines, 1981). Clearly, scores on any single scale must vary along a common construct in order to be interpretable (Gardner, 1995; 1996), but the extent to which attitude data is unidimensional or multidimensional had not reached a consensus despite the vast amount of research that has since assumed a unidimensional view. It should be noted that the semantic differential technique (Osgood et al., 1957) allows for multidimensional scaling, but was developed later than the other three techniques.

To reiterate, depending on the theoretical standpoint of the researcher, an 'attitude' is hypothesised to be a single evaluative response (ranging from favourable to unfavourable) based on three different classes of information (Eagly and Chaiken, 1993), or directly comprised of three different classes of information (Breckler, 1984). It is important to mention that other theories on the multidimensionality of attitudes exist, with some arguing that attitudes are two-dimensional 
(Millar and Tesser, 1989; Wilson and Dunn, 1986; Zanna and Rempel, 1988). Importantly, attitude theorists have never formally resolved debate regarding the unidimensional versus tripartite model, or any form of multidimensionality, of attitude structure. Furthermore, there has been recent re-evaluation of attitude structure with regard to the additional utility of measuring more than one dimension (Haddock and Zanna, 1999).

\section{The Re-Emergence of Multidimensionality of Attitudes}

More recently, Haddock and Zanna (1999) have argued that there is a joint role of beliefs (cognitions) and feelings (affect) in the resulting evaluative dimension (an 'attitude'). Examples of the differential role of different sources of information are highlighted in studies where individuals hold opposing views towards a target at the same time. Lavine et al. (1998) analysed the national survey data of four American elections and found that when cognitive information was of an opposite valence to affective information (ambivalent), voters reported relying on feelings (affect). When cognitive and affective information were consistent with each otherboth positive or negative (univalent)-both sources of information were considered to equally influence the resulting reported behaviour (reported voting choice). Results such as these indicate the importance of not assuming unidimensionality of attitudes. Attitude ambivalence research indicates the importance of scoring affect and cognitive attitude information separately (and not creating a total summated score of 'attitudes'). To take this further, it is argued here that behavioural information should also be scored separately to further develop attitude ambivalence theory. Behavioural information as it relates to attitudes are the tendencies to engage in particular behaviours regarding the attitudinal target. It is distinct from behaviour; it is what we believe we do rather than what we actually do. The measurement of attitudes is also now very popular in a variety of fields, such as in empirical aesthetics and applied aesthetics, with researchers implementing more multidimensional aspects beyond just asking for preference or beauty (Faerber et al., 2010). It may be that the investigation of explicit attitudes should be combined or complemented with implicit approaches (such as processing fluency; Albrecht and Carbon, 2014; Reber et al., 2004) in which response scaling issues will not be a concern. There is also a multidimensional version (the md-IAT; Gattol et al., 2011) of the implicit attitudes test proposed by Greenwald et al. (1998) representing an additional possibility for multidimensional attitudes research.

\section{Some Outstanding Attitude Problems}

Examination of the history of the attitude concept indicates that the unidimensionality of attitude structure cannot be assumed. Attitudes are likely to be multidimensional, although the number of dimensions is not clear (Breckler, 1984; Breckler and Wiggins, 1989; Diab, 1967; Katz and Stotland, 1959; Millar and Tesser, 1989; Ostrom, 1969; Rosenberg and Hovland, 1960; Smith, 1947; Triandis, 1967; Wilson and Dunn, 1986; Woelfel et al., 1980; Zanna and Rempel, 1988). The likely multidimensionality of attitudes coupled with the simultaneous use of unidimensional Likert scaling is a cause for concern. It may be problematic to assume that attitudes can be adequately measured using a Likert scale and Likert response format for two reasons. Firstly, if there are multiple components/dimensions to attitudes, what do results on a single scale indicate? Results from a single scale should represent a single construct for the data to be useful and interpretable (Gardner 1995; 1996; Carifio and Perla, 2007). Specifically, the main assumptions when using the Likert scale is that there is a logical, conceptual or empirical underpinning to the items chosen for the scale (Likert, 1932; Carifio and Perla, 2007) and items are required to be replications of each other for the scale to be interpretable (Alphen et al., 1994). If attitudes are multidimensional, a single Likert scale is not feasible as the assumptions are not met. Should studies not include separate Likert scales with different response formats for each component? Secondly, even if three separate Likert scales (affective, behavioural, cognitive) are used to measure attitudes, what evidence is there that all three components can be adequately represented along a Likert response format ranging from positive to negative. For example, cognitive information may not be positive or negative, but semantic and best represented on a semantic differential scale. Thirdly, given the genesis of the Likert scale and Likert response format from the affective component of attitudes, we may be only or disproportionately capturing emotional (affective) information when we use Likert scales and Likert response formats to measure attitudes. Regardless of how many dimensions in attitudes, the use of Likert scales with a Likert response format in which all items are summed into a single score ranging from positive to negative, prohibits examination of the multidimensionality of the data in two ways: Firstly, the attitudes themselves may be multidimensional (e.g., affective, behavioural and/or cognitive) and secondly, the responses may be multidimensional (e.g., content-by-intensity). It is therefore proposed that Likert scales with Likert response formats may oversimplify attitude data. Furthermore, if attitudes are multidimensional, the use of unidimensional scaling is likely to produce meaningless score data (Gardner, 1996). 


\section{Conclusion}

This article has indicated that, in the past, attitude researchers were aware that Likert scaling treats the affective component as the whole attitude (Fishbein, 1967; Ostrom, 1969; Triandis 1967) and misses much of the behavioural and cognitive information of attitudes. Recent research typically ignores the possible multidimensionality of attitudes by choosing to measure attitudes through unidimensional scaling. Therefore, it is often assumed that Likert scales and Likert response formats are adequate for measuring (possibly) multidimensional data with little evidence. Prior to the wide adoption of the unidimensional scale, attitudes could be better measured by multiple scales with corresponding response formats. Affective scales may be measured with like-dislike response formats; behavioural information may be measured with level or extent of engagement with the attitudinal target; cognitive information may be measured with a semantic differential or an open response format. Crucially, it is expected that a single value (summated scores from all three scales) will not usefully represent the attitudes data.

\section{Acknowledgement}

The support and funding from the ESRC is gratefully acknowledged.

\section{Funding Source Statement}

The study was funded by an Economic and Social Research Council Studentship award to the author. The funding source had no involvement in the ideas, analysis, interpretation, nor in the writing of the report; and in the decision to submit the article for publication.

\section{Ethics}

There are no foreseen ethical implications of the article. The article is a review and did not require ethical approval.

\section{References}

Ajzen, I., 2014. Attitude Structure and Behavior. In: Attitude Structure and Function, Pratkanis, A., S. Breckler and A. Greenwald (Eds.)., Psychology Press, ISBN-10: 131776658X, pp: 472-472.

Albrecht, S. and C.C. Carbon, 2014. The fluency amplification model: Fluent stimuli show more intense but not evidently more positive evaluations. Acta. Psychol., 148: 195-203.

DOI: $10.1016 /$ j.actpsy.2014.02.002

Allport, G.W., 1979. The Nature of Prejudice. 1st Edn., Addison-Wesley Publishing Company, New York, Doubleday, ISBN-10: 0201001799, pp: 537.
Alphen, A., R. Halfens, A. Hasman and T. Imbos, 1994. Likert or Rasch? Nothing is more applicable than good theory. J. Adv. Nurs., 20: 196-201. DOI: 10.1046/j.1365-2648.1994.20010196.x

Bagozzi, R.P., 1978. The construct validity of the affective, behavioral and cognitive components of attitude by analysis of covariance structures. Multivariate Behav. Res., 13: 9-31. DOI: $10.1207 / \mathrm{s} 15327906 \mathrm{mbr} 13012$

Baum, E.E. and K.M. Nelson, 2007. The effect of a 12month longitudinal long-term care rotation on knowledge and attitudes of internal medicine residents about geriatrics. J. Am. Direc. Assoc. 8: 105-109. DOI: 10.1016/j.jamda.2006.05.009

Bell, D.W., V.M. Esses and G.R. Maio, 1996. The utility of open-ended measures to assess intergroup ambivalence. Canadian J. Behav. Sci. Revue Canadienne Des Sci. du Comportement, 28: 12-18. DOI: 10.1037/0008-400X.28.1.12

Breckler, S.J. and E.C. Wiggins, 1989. On Defining Attitude and Attitude Theory. In: Attitude Structure and Function, Pratkanis, A.R., S.J. Breckler and A.G. Greenwald (Eds.)., Psychology Press, ISBN10: 131776658X, pp: 472-472.

Breckler, S.J., 1984. Empirical validation of affect, behavior and cognition as distinct components of attitude. J. Personality Social Psychol., 47: 11911205. DOI: 10.1037/0022-3514.47.6.1191

Campbell, D.T. and D.W. Fiske, 1959. Convergent and discriminant validation by the multitraitmultimethod matrix. Psychol. Bulletin, 56: 81-105. DOI: $10.1037 / \mathrm{h} 0046016$

Carifio, J. and R.J. Perla, 2007. Ten common misunderstandings, misconceptions, persistent myths and urban legends about Likert scales and Likert response formats and their antidotes. J. Social Sci., 3: 106-116. DOI: 10.3844/jssp.2007.106.116

DeFleur, M.L. and F.R. Westie, 1963. Attitude as a scientific concept. Social Forces, 42: 17-31. DOI: $10.2307 / 2574941$

Diab, L.N., 1967. Measurement of Social Attitudes: Problems and Prospects. In: Attitude, Egoinvolvement and Change, Sherif, C.W. and M. Sherif (Eds.)., Greenwood Press, Westport, pp: 316-316.

Duncan, O.D. and M. Stenbeck, 1987. Are likert scales unidimensional. Social Sci. Res., 16: 245-259. DOI: 10.1016/0049-089X(87)90003-2

Eagly, A.H. and S. Chaiken, 1993. The Psychology of Attitudes. 1st Edn., Harcourt Brace Jovanovich College Publishers, Belmont, ISBN-10: 0155000977, pp: 794.

Edwards, A.L., 1957. Techniques of Attitude Scale Construction. 1st Edn., Ardent Media, New York, ISBN-10: 0829000674, pp: 256. 
Esses, V.M. and G.R. Maio, 2002. Expanding the assessment of attitude components and structure: The benefits of open-ended measures. Eur. Rev. Social Psychol., 12: 71-101. DOI: $10.1080 / 14792772143000021$

Esses, V.M., G. Haddock and M.P. Zanna, 1994. The Role of Mood in the Expression of Intergroup Stereotypes. In: The Psychology of Prejudice: The Ontario Symposium, Zanna, M.P. and J. Olson (Eds.)., Psychology Press, ISBN-10: 1134769938, pp: 360.

Faerber, S.J., H. Leder, G. Gerger and C.C. Carbon, 2010. Priming semantic concepts affects the dynamics of aesthetic appreciation. Acta Psychologica, 135: 191200. DOI: $10.1016 /$ j.actpsy.2010.06.006

Fazio, R.H., 2007. Attitudes as object-evaluation associations of varying strength. Social Cognit., 25: 603-637. DOI: 10.1521/soco.2007.25.5.603

Fishbein, M., 1967. Attitude and the Prediction of Behavior. In: Readings in Attitude Theory and Measurement, M. Fishbein (Ed.)., Wiley, New York, ISBN-10: 047126055X, pp: 499.

Gardner, P.L., 1995. Measuring attitudes to science: Unidimensionality and internal consistency revisited. Res. Sci. Educ., 25: 283-289. DOI: $10.1007 / \mathrm{BF} 02357402$

Gardner, P.L., 1996. The dimensionality of attitude scales: A widely misunderstood idea. Int. J. Sci. Educ., 18: 913-919. DOI: 10.1080/0950069960180804

Gattol, V., M. Saaksjarvi and C.C. Carbon, 2011. Extending the Implicit Association Test (IAT): Assessing consumer attitudes based on multidimensional implicit associations. PLoS ONE, 6: 15849-15849. DOI: 10.1371/journal.pone.0015849

Gjersing, L., Waal, H., Caplehorn, J.R.M., Gossop, M., Clausen, T., 2010. Staff attitudes and the associations with treatment organisation, clinical practices and outcomes in opioid maintenance treatment. BMC Health Serv. Res. 10: 194.

DOI: $10.1186 / 1472-6963-10-194$

Greenwald, A.G., D.E. McGhee and J.L.K. Schwartz, 1998. Measuring individual differences in implicit cognition: The implicit association test. J. Personality Social Psychol., 74: 1464-1480. DOI: $10.1037 / 0022-3514.74 .6 .1464$

Guilford, J.P., 1954. Psychometric Methods. 2nd Edn., McGraw-Hill, London, pp: 597.

Guttman, L.A., 1944. A basis for scaling qualitative data. Am. Sociol. Rev., 9: 139-150. DOI: 10.2307/2086306

Haddock, G. and M.P. Zanna, 1998. On the use of openended measures to assess attitudinal components. Bri. J. Social Psychol., 37: 129-149. DOI: $10.1111 / \mathrm{j} .2044-8309.1998 . t b 01161 . x$
Haddock, G. and M.P. Zanna, 1999. Cognition, affect and the prediction of social attitudes. Eur. Rev. Social Psychol., 10: 75-99.

DOI: $10.1080 / 14792779943000026$

Katz, D. and E. Stotland, 1959. A Preliminary Statement to a Theory of Attitude Structure and Change. In: Psychology: A Study of a Science, Koch, S. (Ed.)., McGraw-Hill, New York, pp: 423-475.

Lavine, H., C.J. Thomsen, M.P. Zanna and E. Borgida, 1998. On the primacy of affect in the determination of attitudes and behaviour: The moderating role of affective-cognitive ambivalence. J. Exp,. Social Psychol., 34: 398421. DOI: $10.1006 /$ jesp. 1998.1357

Likert, R., 1932. A technique for the measurement of attitudes. Archives Psychol., 22: 1-55.

Macknight, C. and C. Powell, 2001. The effect of a home visit on first year medical students attitudes towards older adults. Geriatrics Today: J. Can. Geriatr Soc., 4: 182-185.

McIver, J. and E.G. Carmines, 1981. Unidimensional Scaling. 1st Edn., SAGE Publications, Newbury Park, ISBN-10: 0803917368, pp: 96.

Millar, M.G. and A. Tesser, 1989. The effects of affectivecognitive consistency and thought on the attitudebehavior relation. J. Exp. Social Psychol., 25: 189-202. DOI: 10.1016/0022-1031(89)90012-7

Nelson, E., 1939. Attitudes: Their nature and development. J. General Psychol., 21: 367-399. DOI: $10.1080 / 00221309.1939 .10544304$

Osgood, C.E., G.J. Suci and P.H. Tannenbaum, 1957. The Measurement of Meaning. 1st Edn., University of Illinois Press, Urbana, ISBN-10: 0252745396, pp: 342.

Ostrom, T.M., 1968. The Emergence of Attitude Theory: 1930-1950. In: Psychological Foundations of Attitudes, Greenwald, A.G., T.C. Brock and T.M. Ostrom (Eds.)., Taylor and Francis Group, New York, pp: 424-424.

Ostrom, T.M., 1969. The relationship between the affective, behavioral and cognitive components of attitude. J. Exp. Social Psychol., 5: 12-30. DOI: 10.1016/0022-1031(69)90003-1

Reber, R., N. Schwarz and P. Winkielman, 2004. Processing fluency and aesthetic pleasure: Is beauty in the perceiver's processing experience. Personality Social Psychol. Rev., 8: 364-382. DOI: $10.1207 /$ s15327957pspr0804_3

Reuben, D.B., M. Lee, J.W. Davis, M.S. Eslami and D.G. Osterweil et al., 1998. Development and validation of a geriatrics attitudes scale for primary care residents. J. Am. Geriatr Soc., 46: 1425-1430. 
Rosenberg, M.J. and C.I. Hovland, 1960. Cognitive, Affective and Behavioral Components of Attitudes. In: Attitude Organization and Change: An Analysis of Consistency among Attitude Components, Rosenberg, M.J., C.I. Hovland, W.J. McGuire, R.P. Abelson and J.W. Brehm (Eds.)., Greenwood Press, New Haven, Westport, pp: 239-239.

Sherif, C.W., M. Sherif and R.E. Nebergall, 1965. Attitude and Attitude Change: The Social Judgmentinvolvement Approach. 1st Edn., Greenwood Press, Westport, ISBN-10: 0313232601, pp: 264.

Smith, M.B., 1947. The personal setting of public opinions: A study of attitudes toward Russia. Public Opin. Q., 11: 507-523. DOI: 10.1093/poq/11.4.507

Tesser, A. and D.R. Shaffer, 1990. Attitudes and attitude change. Ann. Rev. Psychol., 41: 479-523. DOI: 10.1146/annurev.ps.41.020190.002403

Thurstone, L.L. and E.J. Chave, 1929. The Measurement of Attitude: A Psychophysical Method and Some Experiments, with a Scale for Measuring Attitude toward the Church. 8th Edn., University of Chicago Press, Chicago, pp: 96.

Thurstone, L.L., 1928. Attitudes can be measured. J. Sociol., 33: 529-554. DOI: 10.1086/214483
Triandis, H.C., 1967. Toward an Analysis of the Components of Interpersonal Attitudes. In: Attitude, Ego-involvement and Change, Sherif, C.W. and M. Sherif (Eds.)., Greenwood Press, London, Wiley, pp: 316-316.

Wånggren, K., J. Alden, T. Bergh and A.S. Svanberg, 2013. Attitudes towards embryo donation among infertile couples with frozen embryos. Hum. Reprod. 28: 24322439. DOI: $10.1093 /$ humrep/det252

Wilson, T.D. and D.S. Dunn, 1986. Effects of introspection on attitude-behavior consistency: Analyzing reasons versus focusing on feelings. J. Exp. Soc. Psychol., 22: 249-263. DOI: 10.1016/0022-1031(86)90028-4

Woelfel, J., J. Gillham, M.J. Cody and R.A. Holmes, 1980. Basic premises of multidimensional attitude change theory: An experimental analysis. Human Commun. Res., 6: 153-167. DOI: $10.1111 /$ j.1468-2958.1980.tb00135.x

Zanna, M.P. and J.K. Rempel, 1988. Attitudes: A New Look at an Old Concept. In: The Social Psychology of Knowledge, Bar-Tal D. and A.W. Kruglanski (Eds.)., Cambridge University Press, Cambridge, ISBN-10: 052132114X, pp: 399-399.

Zanna, M.P., 1990. Attitude functions: Is it related to attitude structure. Adv. Consumer Res., 17: 98-100. 